\title{
Sphingosine-1-Phosphate Aggravates Antigen-Induced Airway Inflammation in Mice
}

\author{
Yoshihiko Chiba*, Kanako Suzuki, Eriko Kurihara, Miho Uechi, \\ Hiroyasu Sakai and Miwa Misawa
}

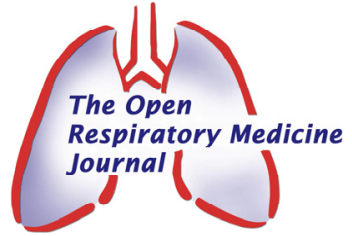

Department of Pharmacology, School of Pharmacy, Hoshi University, Tokyo, Japan

\begin{abstract}
Recent investigations suggest an involvement of sphingosine-1-phosphate (S1P) in the pathogenesis of allergic bronchial asthma. However, the role of S1P in the development of asthma is still controversial. Our aim was to investigate the effects of intranasal application of S1P on antigen-induced airway inflammation in a mouse model of allergic bronchial asthma.

Methodology: Male BALB/c mice were actively sensitized with ovalbumin antigen, and were repeatedly challenged with aerosolized antigen. Animals also received an intranasal administration of S1P $\left(10^{-5} \mathrm{M}, 20 \mu \mathrm{L}\right)$ or its vehicle $(1 \%$ methanol in sterile PBS, $20 \mu \mathrm{L}) 30 \mathrm{~min}$ prior to each antigen challenge. Histological examinations of the lungs and determination of cell number in the bronchoalveolar lavage fluids (BALFs) were studied.

Results: The airway inflammation induced by antigen exposure was significantly augmented by the intranasal administration of S1P: the cell number in BALFs of the S1P-treated, antigen-challenged mice (S1P-Challenged, $48.9 \pm 4.8$ $\mathrm{x} 10^{4} / \mathrm{mL}$ BALF) was significantly increased as compared with those of the vehicle-treated, antigen-challenged ones (Vehicle-Challenged, 26.3 $\pm 5.7 \times 10^{4} / \mathrm{mL}$ BALF, $\mathrm{P}<0.01$ ).

Conclusion: In mice, the intranasal administration of S1P might aggravate the antigen-induced airway inflammation.
\end{abstract}

Keywords: Sphingosine-1-phosphate (S1P), intranasal administration, allergic bronchial asthma, airway inflammation, mouse.

\section{INTRODUCTION}

The dramatic increase in the number of asthma cases over the last decades is of great concern for public health in the world [1]. Allergic bronchial asthma is characterized by structural and functional abnormalities of the bronchial epithelium, accumulation of inflammatory cells in the bronchial mucosa, remodeling of the airway tissue structure, and airway hyperresponsiveness. Many mediators have been identified that play significant roles in the initiation and progression of the disease, but the exact mechanism of the pathogenesis of asthma is still unclear.

Sphingosine-1-phosphate (S1P) is a bioactive sphingolipid metabolite that mediates diverse biological responses [2-6]. Recently, an involvement of S1P in allergic bronchial asthma has been suggested [7-13]. Ammit and colleagues [7] firstly demonstrated that S1P levels are elevated in the airways of individuals with asthma after segmental allergen challenge. The finding that $\mathrm{S} 1 \mathrm{P}$ can act as a chemotactic agent for eosinophils further suggests an involvement of S1P in pathophysiology of asthma [8]. Indeed, inhalation of inhibitors for sphingosine kinase (SphK), which produces S1P directly from sphingosine, attenuated antigen-induced airway inflammation in mice [9]. In addition, S1P might have an ability to cause airway hyperresponsiveness [10-13], one of the characteristic

*Address correspondence to this author at the Department of Pharmacology, School of Pharmacy, Hoshi University, 2-4-41 Ebara, Shinagawa-ku, Tokyo 142-8501, Japan; Tel: 81-3-5498-5786; Fax: 81-3-5498-5787;

E-mail: chiba@hoshi.ac.jp features of allergic bronchial asthma. Contrary to these observations, an intratracheal instillation of FTY720, an S1P receptor agonist, prevented antigen-induced airway inflammation and hyperresponsiveness in mice [14]. Thus, the role of S1P in the development of asthma is still controversial.

In the present study, the effects of pretreatment with S1P by intranasal administration on antigen-induced inflammatory signs of the airways were determined in a murine model of allergic bronchial asthma.

\section{METHODS}

\section{Animals and Treatments}

Male BALB/c mice were purchased from the Charles River Japan, Inc. (Kanagawa, Japan) and housed in a pathogen-free facility. All animal experiments were approved by the Animal Care Committee of the Hoshi University (Tokyo, Japan).

Preparation of a murine model of allergic bronchial asthma, which has an in vivo AHR [15], was performed as described previously [16-20]. In brief, BALB/c mice ( 8 weeks of age) were actively sensitized by intraperitoneal injections of $8 \mu \mathrm{g}$ ovalbumin (OA; Seikagaku Co., Tokyo, Japan) with $2 \mathrm{mg}$ Imject Alum (Pierce Biotechnology, Inc., Rockfold, IL, USA) on Day 0 and Day 5. The sensitized mice were challenged with aerosolized OA-saline solution (5 $\mathrm{mg} / \mathrm{mL}$ ) for $30 \mathrm{~min}$ on Days 12, 16 and 20. The OA aerosol was generated with an ultrasonic nebulizer (Nihon Kohden, Tokyo, Japan) and introduced to a Plexiglas chamber box 
$(130 \times 200 \mathrm{~mm}, 100 \mathrm{~mm}$ height) in which the mice were placed. The animals also received intranasal administration of S1P $\left(10^{-5} \mathrm{M}, 20 \mu \mathrm{L}\right)$ or its vehicle $(1 \%$ methanol in sterile PBS, $20 \mu \mathrm{L}) 30 \mathrm{~min}$ prior to each antigen challenge by the method previously described [18]. The dose of S1P was decided based on the previous report [7]. Twenty-four hours after the last OA challenge, mice were sacrificed by exsanguination from abdominal aorta under urethane (1.6 $\mathrm{g} / \mathrm{kg}$, i.p.; Sigma and Aldrich, St. Louis, MO) anesthesia. Then histologic examination and cell count in bronchoalveolar lavage (BAL) fluid were carried out by the methods previously described [18].

\section{Statistical Analyses}

The cell counts data were expressed as the mean with S.E. Statistical significance of difference was determined by unpaired Student's $t$-test or two-way analysis of variance (ANOVA) with post hoc Bonferroni/Dunn (StatView for
Macintosh ver. 5.0, SAS Institute, Inc., NC). A value of $\mathrm{p}<0.05$ was considered significant.

\section{RESULTS AND DISCUSSION}

In the present study, we used our well-established murine model of allergic bronchial asthma [16-20]. Histochemical examination using hematoxylin and eosin staining revealed a marked lung inflammation in the repeatedly antigenchallenged mice (Fig. 1C) as compared with the control animals (Fig. 1A): a marked infiltration of inflammatory cells, mainly eosinophils, was observed in the lungs of the antigen-challenged mice. The inflammation score determined as previously described [19] was significantly increased in lungs of the antigen-challenged mice $(2.4 \pm 0.4)$ than that of the control animals $(0.9 \pm 0.3, \mathrm{P}<0.05)$. To further quantify the airway inflammation, cell counts in bronchoalveolar lavage (BAL) fluids were carried out. As shown in Fig. (2), the cell counts in BAL fluids of the repeatedly antigen-
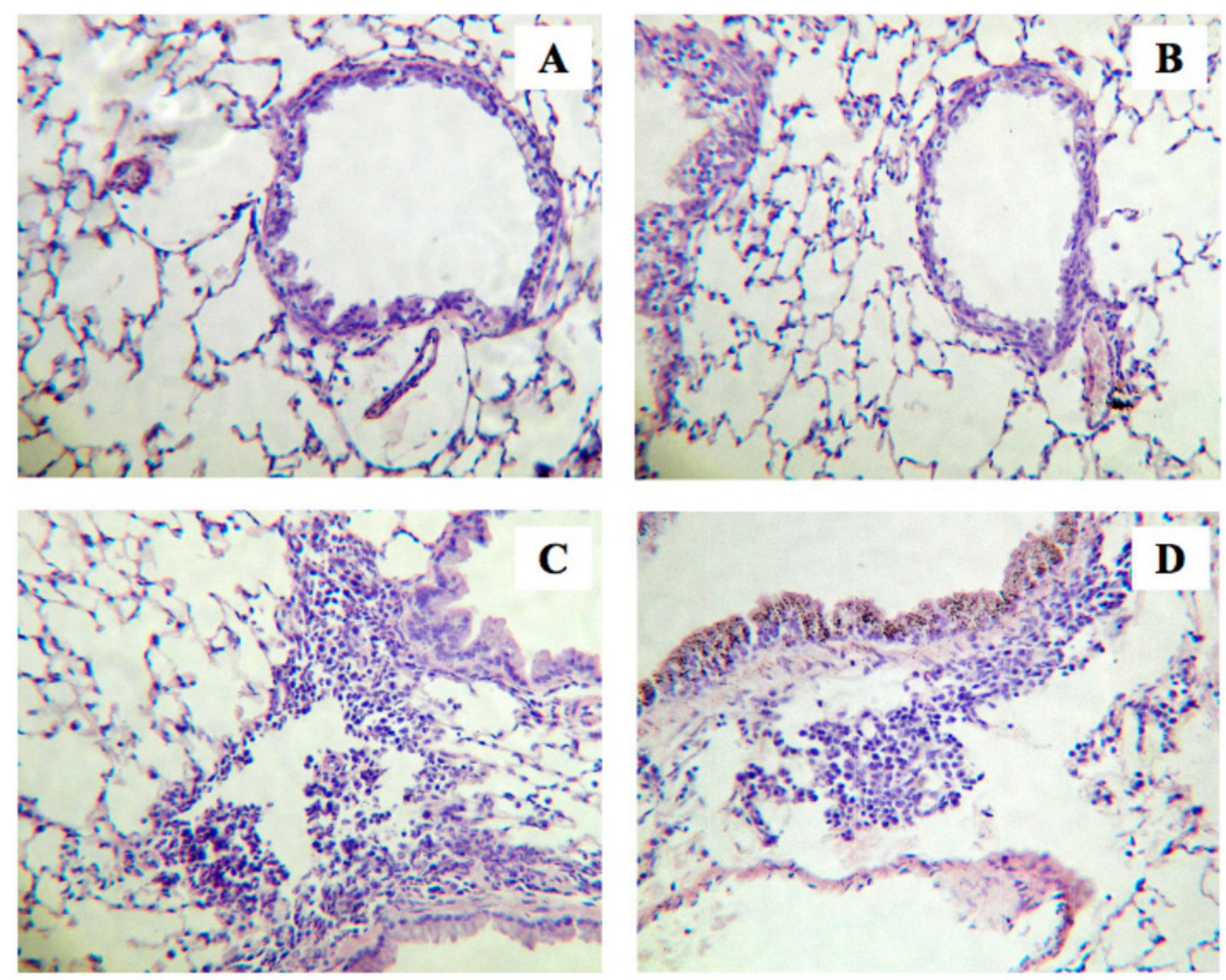

Fig. (1). Histological examinations of lungs from the repeatedly antigen-challenged (Challenged; $\mathbf{C}$ and $\mathbf{D})$ and control mice (Control; $\mathbf{A}$ and B). Animals were also received intranasal administration of sphingosine-1-phosphate (S1P; $\left.10^{-5} \mathrm{M}, 20 \mu \mathrm{L}\right)$ or its vehicle $(1 \%$ methanol in sterile PBS, $20 \mu \mathrm{L}) 30 \mathrm{~min}$ prior to each antigen exposure. Four- $\mu \mathrm{m}$ sections of formalin-fixed lung tissues were stained with hematoxylin and eosin before examination by light microscopy. The photos shown are Vehicle-Control (A), S1P-Control (B), Vehicle-Challenged (C), and S1P-Challenged groups (D), and are representative of 3 different animals, respectively. Original magnification: x80. 
challenged mice were significantly increased as compared with those of the control group (Fig. 2, Vehicle-Control vs Vehicle-Challenged groups; $\mathrm{P}<0.05)$. As previously reported $[19,20]$, most of the increased cells were eosinophils. The vehicle used had no effect on baseline lung histology and BAL cell counts and the airway inflammation induced by antigen exposure (data not shown).
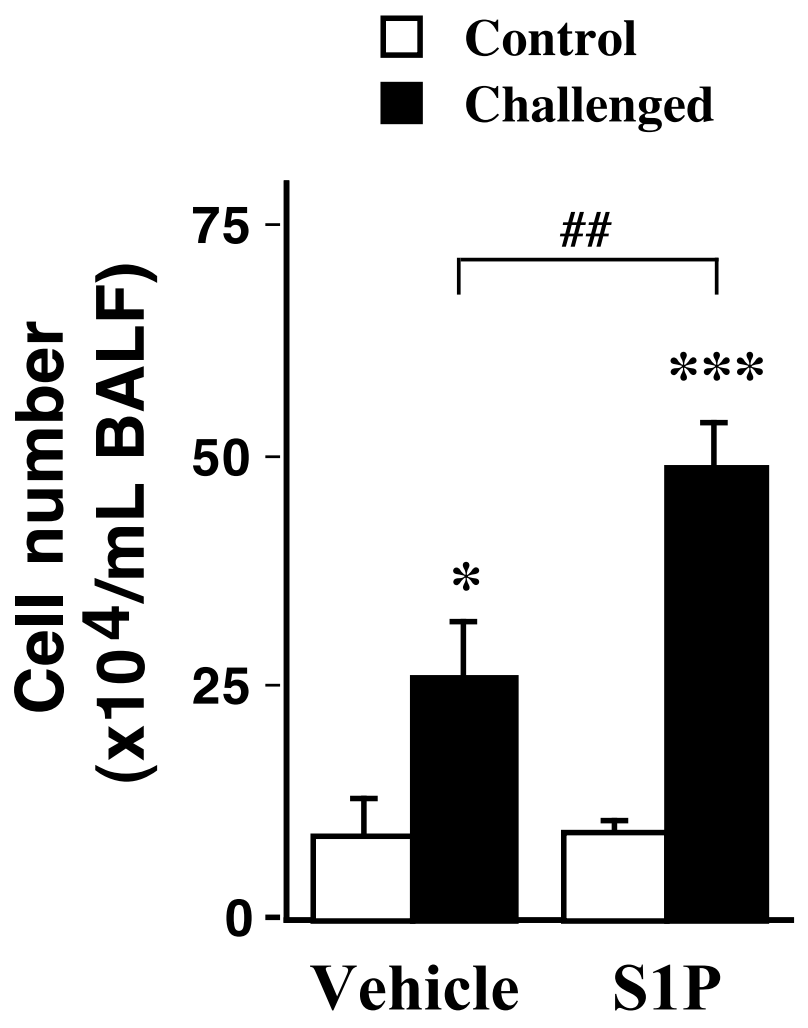

Fig. (2). Effects of intranasally administered sphingosine-1phosphate (S1P; $\left.10^{-5} \mathrm{M}, 20 \mu \mathrm{L}\right)$ on cell number in bronchoalveolar lavage fluids (BALFs) obtained from control (Control) and repeatedly antigen-challenged (Challenged) mice. Each column represents the mean with SEM from 3 (Vehicle-Control) and 5 (the others) different animals. $* P<0.05$ vs Vehicle-Control and $* * * P<$ 0.001 vs S1P-Challenged by Bonferroni/Dunn's test. The antigeninduced increase in cell number was significantly augmented by the S1P treatment (Vehicle-Challenged vs S1P-Challenged, ${ }^{\# \#} P<0.01$ by Bonferroni/Dunn's test).

Recently, an involvement of sphingosine-1-phosphate (S1P) in the pathogenesis of allergic bronchial asthma has been suggested by the fact that S1P levels are elevated in the airways of asthmatics [7]. The current study revealed that, although the S1P administration alone had no effect on the lung histology (Fig. 1A, B) and the BAL cell counts in control animals (Fig. 2, Vehicle-Control vs S1P-Control), administration of $\mathrm{S} 1 \mathrm{P}$ prior to each antigen challenge aggravated the antigen-induced increase in BAL cell counts in mice (Fig. 2, Vehicle-Challenged vs S1P-Challenged groups; $\mathrm{P}<0.01)$. Different cell counts using Diff-Quik staining [19] revealed that the cell composition in BAL fluids of the S1P-Challenged group (macrophages: $47.1 \pm 9.9 \%$, eosinophils: $\quad 38.6 \pm 6.2 \%$, lymphocytes: $12.1 \pm 2.5 \%$, and neutrophils: $2.2 \pm 1.1 \%$ ) was similar to that of the Vehicle-Challenged one $(48.9 \pm 10.1 \%, \quad 37.8 \pm 5.6 \%$,
$11.1 \pm 2.2 \%$ and $2.2 \pm 1.2 \%$, respectively). An increase in the inflammation score was also observed in the lungs of the S1P-Challenged group $(2.8 \pm 0.5)$, although the difference was not statistically significant when compared with that of the Vehicle-Challenged one $(2.4 \pm 0.4, \mathrm{P}>0.05)$. The results that S1P aggravated antigen-induced airway inflammation might be consistent with the previous report that pharmacological inhibition of sphingosine kinase (SphK) attenuated airway inflammation in mouse experimental asthma [9]. It is thus possible that endogenously released $\mathrm{S} 1 \mathrm{P}$ is one of the mediators that play significant roles in the initiation and/or progression of allergic bronchial asthma.

Contrary to our results, Idzko and colleagues [14] reported that an intratracheal instillation of FTY720, an S1P receptor agonist, or S1P itself prior to each antigen inhalation abolished inflammatory cells infiltration into the airways in the BALB/c mice. Although the reason for the discrepancy is not known for certain, differences in the experimental conditions, such as difference in the protocols for antigen sensitization and inhalation, difference in the concentration and volume of S1P solution $\left(20 \mu \mathrm{L}\right.$ of $10^{-5} \mathrm{M}$ currently vs $80 \mu \mathrm{L}$ of $10^{-6} \mathrm{M}$ in their study), and/or difference in the administration route of S1P (intranasally $v s$ intratracheally, respectively), might be involved in it. While S1P and/or S1P receptor agonists, such as FTY720, have been suggested as a novel therapeutic strategy for airway inflammation [14, 21], further studies are required for making clear the exact role of S1P in the pathogenesis of allergic bronchial asthma.

In summary, the intranasal application of S1P caused an aggravation of airway inflammation induced by antigen exposure in a mouse model of allergic bronchial asthma. The results might raise a caution for clinical use of $\mathrm{S} 1 \mathrm{P}$ receptor agonists, such as FTY720, in asthma treatment.

\section{CONFLICT OF INTEREST STATEMENT}

None of the authors have a financial relationship with a commercial entity that has an interest in the subject of this manuscript.

\section{REFERENCES}

[1] Eder W, Ege MJ, von Mutius E. The asthma epidemic. N Engl J Med 2006; 355: 2226-35.

[2] Ohmori T, Yatomi Y, Osada M, et al. Sphingosine 1-phosphate induces contraction of coronary artery smooth muscle cells via S1P2. Cardiovasc Res 2003; 58: 170-7.

[3] Lorenz JN, Arend LJ, Robitz R, Paul RJ, MacLennan AJ. Vascular dysfunction in S1P2 sphingosine 1-phosphate receptor knockout mice. Am J Physiol Regul Integr Comp Physiol 2007; 292: R440-6.

[4] Murakami A, Takasugi H, Ohnuma S, et al. Sphingosine 1phosphate regulates vascular contraction via S1P3 receptor: investigation based on a new S1P3 receptor antagonist. Mol Pharmacol 2010; 77: 704-13.

[5] Song HJ, Choi TS, Chung FY, et al. Sphingosine 1-phosphateinduced signal transduction in cat esophagus smooth muscle cells. Mol Cells 2006; 21: 42-51.

[6] Hu W, Mahavadi S, Huang J, Li F, Murthy KS. Characterization of S1P1 and S1P2 receptor function in smooth muscle by receptor silencing and receptor protection. Am J Physiol Gastrointest Liver Physiol 2006; 291: G605-10.

[7] Ammit AJ, Hastie AT, Edsall LC, et al. Sphingosine 1-phosphate modulates human airway smooth muscle cell functions that promote inflammation and airway remodeling in asthma. FASEB J 2001; 15: 1212-4. 
[8] Roviezzo F, Del Galdo F, Abbate G, et al. Human eosinophil chemotaxis and selective in vivo recruitment by sphingosine 1phosphate. Proc Natl Acad Sci USA 2004; 101: 11170-5.

[9] Nishiuma T, Nishimura $Y$, Okada $T$, et al. Inhalation of sphingosine kinase inhibitor attenuates airway inflammation in asthmatic mouse model. Am J Physiol Lung Cell Mol Physiol 2008; 294: L1085-93.

[10] Roviezzo F, Di Lorenzo A, Bucci M, et al. Sphingosine-1phosphate/sphingosine kinase pathway is involved in mouse airway hyperresponsiveness. Am J Respir Cell Mol Biol 2007; 36: 757-62.

[11] Kume H, Takeda N, Oguma T, et al. Sphingosine 1-phosphate causes airway hyper-reactivity by rho-mediated myosin phosphatase inactivation. J Pharmacol Exp Ther 2007; 320: 766-73.

[12] Haberberger RV, Tabeling C, Runciman S, et al. Role of sphingosine kinase 1 in allergen-induced pulmonary vascular remodeling and hyperresponsiveness. J Allergy Clin Immunol 2009; 124: 933-41.

[13] Roviezzo F, D'Agostino B, Brancaleone V, et al. Systemic administration of sphingosine-1-phosphate increases bronchial hyper-responsiveness in the mouse. Am J Respir Cell Mol Biol 2010; 42: 572-7.

[14] Idzko M, Hammad H, van Nimwegen M, et al. Local application of FTY720 to the lung abrogates experimental asthma by altering dendritic cell function. J Clin Invest 2006; 116: 2935-44.

[15] Kato Y, Manabe T, Tanaka Y, Mochizuki H. Effect of an orally active Th1/Th2 balance modulator, M50367, on IgE production, eosinophilia, and airway hyperresponsiveness in mice. J Immunol 1999; 162: 7470-9.

[16] Chiba Y, Tanabe M, Goto K, Sakai H, Misawa M. Downregulation of miR-133a contributes to up-regulation of RhoA in bronchial smooth muscle cells. Am J Respir Crit Care Med 2009; 180: 713-9.

[17] Chiba Y, Todoroki M, Nishida Y, Tanabe M, Misawa M. A novel STAT6 inhibitor AS1517499 ameliorates antigen-induced bronchial hypercontractility in mice. Am J Respir Cell Mol Biol 2009; 41: 516-24.

[18] Chiba Y, Nakazawa S, Todoroki M, Shinozaki K, Sakai H, Misawa M. Interleukin-13 augments bronchial smooth muscle contractility with an up-regulation of RhoA protein. Am J Respir Cell Mol Biol 2009; 40: 159-67.

[19] Chiba Y, Sato S, Misawa M. Lovastatin inhibits antigen-induced airway eosinophilia without affecting the production of inflammatory mediators in mice. Inflamm Res 2009; 58: 363-9.

[20] Chiba Y, Sato S, Misawa M. GGTI-2133, an inhibitor of geranylgeranyltransferase, inhibits infiltration of inflammatory cells into airways in mouse experimental asthma. Int $\mathbf{J}$ Immunopathol Pharmacol 2009; 22: 929-35.

[21] Peng X, Hassoun PM, Sammani S, et al. Protective effects of sphingosine 1-phosphate in murine endotoxin-induced inflammatory lung injury. Am J Respir Crit Care Med 2004; 169: 1245-51.

(c) Chiba et al.; Licensee Bentham Open.

This is an open access article licensed under the terms of the Creative Commons Attribution Non-Commercial License (http://creativecommons.org/licenses/ by-nc/3.0/) which permits unrestricted, non-commercial use, distribution and reproduction in any medium, provided the work is properly cited. 